\title{
əTRMM LIS Climatology of Thunderstorm Occurrence and Conditional Lightning Flash Rates*
}

\author{
DANIEL J. CECIL \\ NASA Marshall Space Flight Center, Huntsville, Alabama \\ DENNIS E. BUECHLER \\ University of Alabama in Huntsville, Huntsville, Alabama \\ RICHARD J. BLAKESLEE \\ NASA Marshall Space Flight Center, Huntsville, Alabama
}

(Manuscript received 9 February 2015, in final form 15 May 2015)

\begin{abstract}
The Lightning Imaging Sensor (LIS) on the Tropical Rainfall Measuring Mission (TRMM) satellite has previously been used to build climatologies of mean lightning flash rate across the global tropics and subtropics. This new work explores climatologies of thunderstorm occurrence as seen by LIS and the conditional mean flash rates when thunderstorms do occur. The region where thunderstorms are seen most often by LIS extends slightly farther east in central Africa than the corresponding region with the highest total mean annual flash rates. Presumably this reflects a difference between more frequent thunderstorm initiation in the east and upscale growth as storms move westward. There are some differences between locations with the greatest total lightning flash counts and those where thunderstorms occur most often. The greatest conditional mean flash rates - considering only those TRMM orbits that do have lightning in a given grid box-are found in subtropical regions. The highest values are in Argentina, with the central United States, Pakistan, eastern China, and the east coast of Australia also having particularly high values.
\end{abstract}

\section{Introduction}

Since late 1997, the Lightning Imaging Sensor (LIS) on the Tropical Rainfall Measuring Mission (TRMM) satellite has enabled examination of lightning flash rates across the global tropics and subtropics. Cecil et al. (2014a) described lightning-flash-rate climatology products from LIS and its predecessor [the Optical Transient Detector (OTD)] that are distributed by NASA. Those products

๖ Denotes Open Access content.

\footnotetext{
* Supplemental information related to this paper is available at the Journals Online website: http://dx.doi.org/10.1175/JCLI-D-150124.s1.

Corresponding author address: Daniel J. Cecil, NASA MSFC Earth Science Office, 320 Sparkman Dr. NW, Huntsville, AL 35805 .

E-mail: danieljcecil@nasa.gov
}

generally compute mean lightning flash rates by accumulating the total number of flashes observed by LIS and the total observation duration for each grid box (either $0.5^{\circ} \times 0.5^{\circ}$ or $2.5^{\circ} \times 2.5^{\circ}$ ) from the thousands of individual TRMM orbits. The observed flash counts are scaled by detection efficiency before computing flash rates, and various subsets are used for characterizing the diurnal cycle or annual cycle. The products have been updated each year, with the most recent release covering the period 1998-2013 (Cecil et al. 2014b).

While updating the LIS gridded climatology products through 2013, some new fields were tested. These include a count of the number of TRMM orbits for which LIS observes each grid box and the number of orbits with lightning observed by LIS for each grid box. Subsets of these as a function of time of day and day of year were also counted. The fraction of observations that have lightning addresses the question of how often thunderstorms occur in a grid box, as distinct from the question of how many lightning flashes occur. The flash rate

DOI: 10.1175/JCLI-D-15-0124.1 
products described by Cecil et al. (2014a) are more relevant to the second question, while this new paper addresses the first question. Dividing the mean flash rates from the Cecil et al. $(2014 a, b)$ products by the fraction of observations with lightning yields a conditional mean flash rate- that is, the mean lightning flash rate for a grid box when lightning does occur, without counting the lightning-free observations. This value is an indication of the relative intensity of the convection occurring within each grid cell.

These new fields characterizing the fraction of TRMM observations with lightning and the conditional mean flash rate will be added to the LIS gridded climatology products for general distribution, during the next update of those products. LIS was shut down on 8 April 2015 in preparation for the TRMM satellite's reentry. The LIS instrument had already experienced substantial downtime during the satellite's power-saving measures in 2014. The next update of the TRMM LIS gridded climatology products will likely occur in late 2015, after quality control of the last TRMM LIS data. The lightning climatology products are available online (http:// lightning.nsstc.nasa.gov/data/data_lis-otd-climatology. html; Cecil et al. 2014b and maintained by the NASA Global Hydrology Resource Center (GHRC). That web page includes data files with corresponding images, animations, documentation, and a Google Earth interface for examining the maps in more detail.

This paper describes the computations of mean flash rate, probability of thunderstorm occurrence, and conditional mean flash rate in section 2. Mean annual values for those fields are mapped in section 3, with discussion of regions having interesting contrasts. Section 4 considers the diurnal cycle, and section 5 summarizes the results.

\section{Data and methods}

Many relevant aspects of the LIS and its data were described by Cecil et al. (2014a). LIS generally observes a location for about $90 \mathrm{~s}$ while the TRMM satellite passes over, with a roughly $600 \mathrm{~km} \times 600 \mathrm{~km}$ field of view for the LIS charge-coupled device (CCD) array. The detection efficiency varies from about $70 \%$ at midday to about $90 \%$ overnight, which is accounted for in the flash rate products. TRMM orbits at $35^{\circ}$ inclination and precesses through the diurnal cycle such that it takes about 46 days for the entire diurnal cycle to be sampled at all grid cells (Negri et al. 2002). So LIS observes the global tropics and subtropics without biases that depend on geography. The most frequent sampling occurs near $\pm 33^{\circ}$ latitude where the spacecraft is moving west to east in an Earth-relative sense and consecutive orbits have overlapping swaths. Through 2013, locations at those latitudes have been observed by LIS for over $400 \mathrm{~h}$ (Fig. 1a) spread across more than 13000 orbits per grid box (Fig. 1b). The deep tropics have been sampled for closer to $130 \mathrm{~h}$, by fewer than 4000 orbits per grid box.

For this analysis, the count of orbits observing a grid box (Fig. 1b) requires that the mean observation duration for that grid box is at least $80 \mathrm{~s}$ in a given orbit. Durations less than 80 s generally result from a grid box being situated along the edge of the swath or from problems with the spacecraft or instrument that result in temporary loss of data. The most common cause of such problems is a temporary overload of the data buffers caused either by electromagnetic noise or by very high lightning flash rates. The former is often associated with the South Atlantic magnetic anomaly, where Earth's magnetic field is weak and an abundance of charged particles can interfere with low-Earth-orbit satellites. This results in the decreased sampling centered on the coast of southeastern Brazil in Fig. 1. In such instances, the instrument records some valid data during the overpass but not enough to treat it as a complete observation.

Dividing the number of observations by the number of observations with lightning gives the fraction of $\sim 90$-s periods with lightning. (While $80 \mathrm{~s}$ is set as the minimum observation duration for each satellite overpass, values are typically between 90 and $100 \mathrm{~s}$.) This is essentially the probability that lightning will be detected in a $0.5^{\circ} \times$ $0.5^{\circ}$ (or $2.5^{\circ} \times 2.5^{\circ}$ ) grid box during an $\sim 90$-s period. Considering the $70 \%-90 \%$ detection efficiency, it can also be thought of as the probability that lightning will occur during a roughly 1-min (or slightly longer) period. Dividing the mean annual flash rate by the fraction of observations with lightning gives a conditional mean flash rate. While mean annual flash rates are presented in flashes per squared kilometers per year, the conditional mean flash rates are presented in flashes per $3000 \mathrm{~km}^{2}$ per minute. The latter is more appropriate for observations of a $0.5^{\circ} \times 0.5^{\circ}$ grid box observed by LIS for just over a minute but accounts for the varying geometrical sizes of these grid boxes with latitude.

The count of orbits (and count of orbits with lightning) for each grid box are not yet subjected to the spatial or temporal smoothing that is applied to flash rate products in Cecil et al. (2014a,b). The smoothing applied to those products (see Table 1 of Cecil et al. 2014a) was originally chosen when the data record spanned only a few years, and less stringent smoothing may be appropriate in some cases. The flash rate products used for comparisons in this paper are only ones with no spatial or temporal smoothing - that is, the mean annual flash rate 
(a)

Hours of Sampling By LIS, 1998-2013

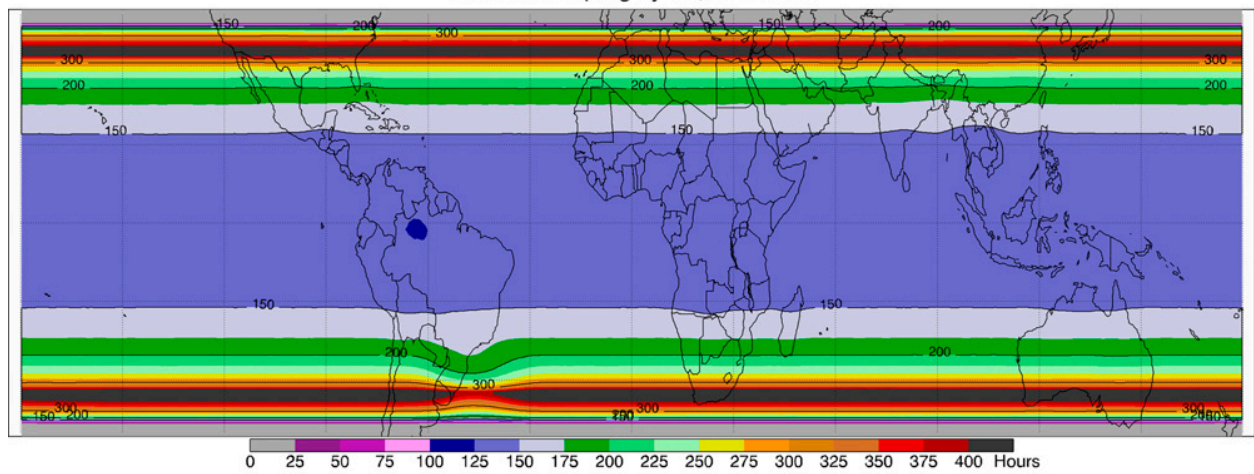

(b)

Number of Orbits Sampling Grid Box At Least $80 \mathrm{~s}$

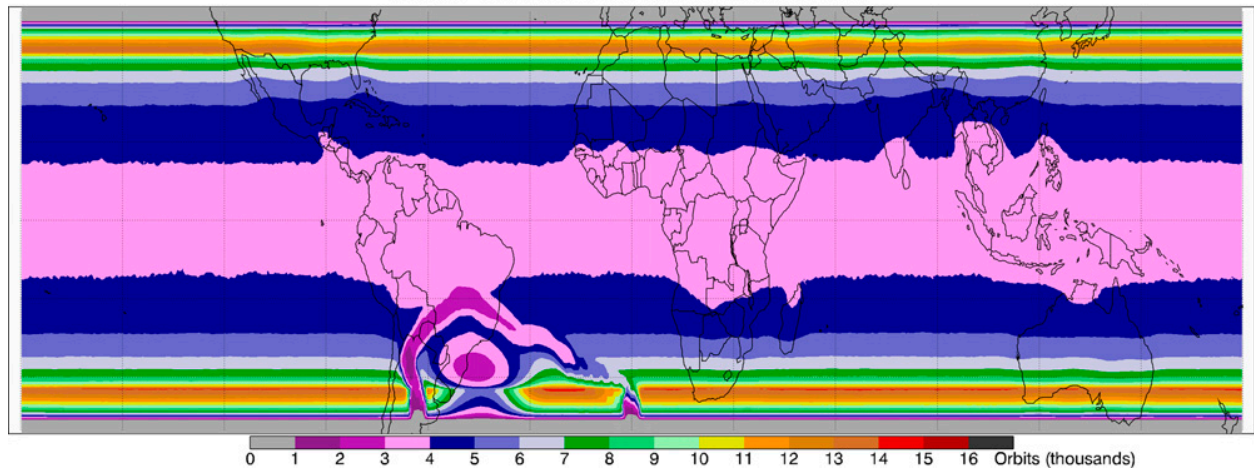

FIG. 1. Total sampling by LIS, 1998-2013. (a) Cumulative observation duration (h). (b) Number of individual orbits to observe each $0.5^{\circ} \times 0.5^{\circ}$ grid box for at least $80 \mathrm{~s}$.

on a $0.5^{\circ} \times 0.5^{\circ}$ grid and the diurnal cycle of flash rate on a $2.5^{\circ} \times 2.5^{\circ}$ grid. Some smoothing would be appropriate in several of the maps shown in this paper, but they are presented at a high resolution to allow subjective smoothing by eye.

\section{Thunderstorm occurrence and conditional mean flash rate}

At first glance, the maps of mean annual flash rate (Fig. 2a) and probability of lightning in a satellite overpass (Fig. 2b) have several similarities. In the deep tropics, maxima in both fields are located in central Africa (Figs. 2 and 3), far northwestern South America (Figs. 2 and 4), and Indonesia (Figs. 2 and 5). Between $5 \%$ and $10 \%$ of observations include lightning within a $0.5^{\circ} \times 0.5^{\circ}$ grid box in those locations. Both fields have large disparities between values over land and over ocean, with almost all oceanic locations having lightning in less than $1 \%$ of observations. These similarities are consistent with Williams et al.'s (2000) conclusion that total climatological lightning flash rates are more responsive to changes in the number of storms, rather than to individual storm flash rates.
Differences are more noteworthy in the subtropical continental regions that have substantial lightning. A good amount of the subtropical United States has mean annual flash rates not much less than those for much of Brazil (Fig. 4)—around 20 flashes per squared kilometer per year. But lightning is seen in about $3 \%$ of observations for much of Brazil, while it is closer to $1 \%$ of the observations for the subtropical United States. A bull'seye in northeastern Argentina and southern Paraguay has over 30 flashes per squared kilometer per year, but less than $2 \%$ of the observations there have lightning in a grid box. Near-coastal regions of Australia (Fig. 6) and eastern China (Fig. 5) have relatively high mean annual flash rates, with a relatively infrequent occurrence of thunderstorms. The regions having $\sim 1 \%$ probability of thunderstorms in Australia (Fig. 6b) roughly correspond to the regions averaging about 30 thunder days per year in the ground-based analysis by Kuleshov et al. (2002).

Those differences are highlighted in the maps of conditional mean flash rates in Figs. 2c, 3c, 4c, 5c, and 6c. When thunderstorms do occur in northern Argentina and Paraguay, the conditional mean flash rate for a $0.5^{\circ} \times 0.5^{\circ}$ grid box is in excess of 12 flashes per minute. 
(a) HRFC_LIS FR

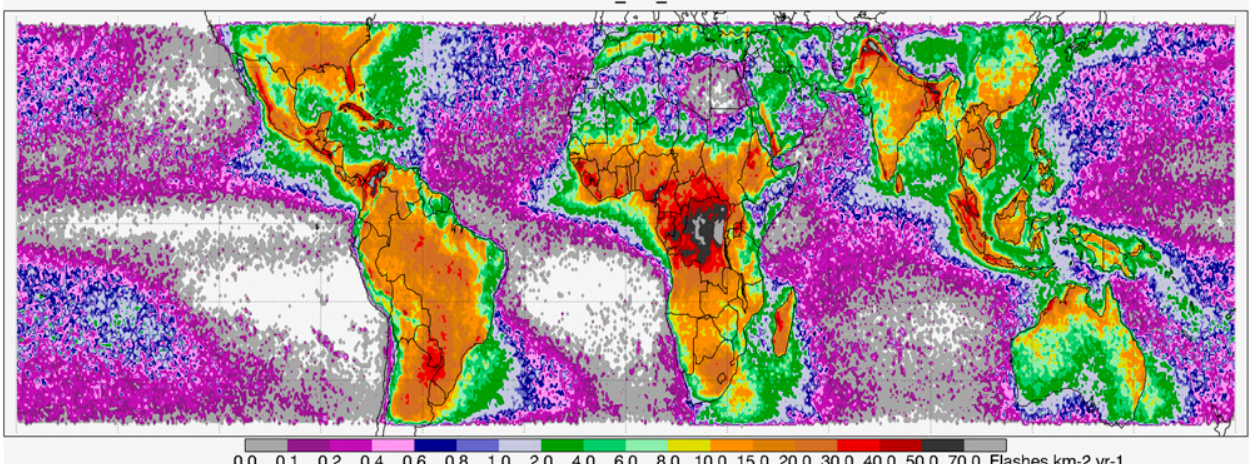

(b) Prob of 1-min lightning in 0.5-degree grid box

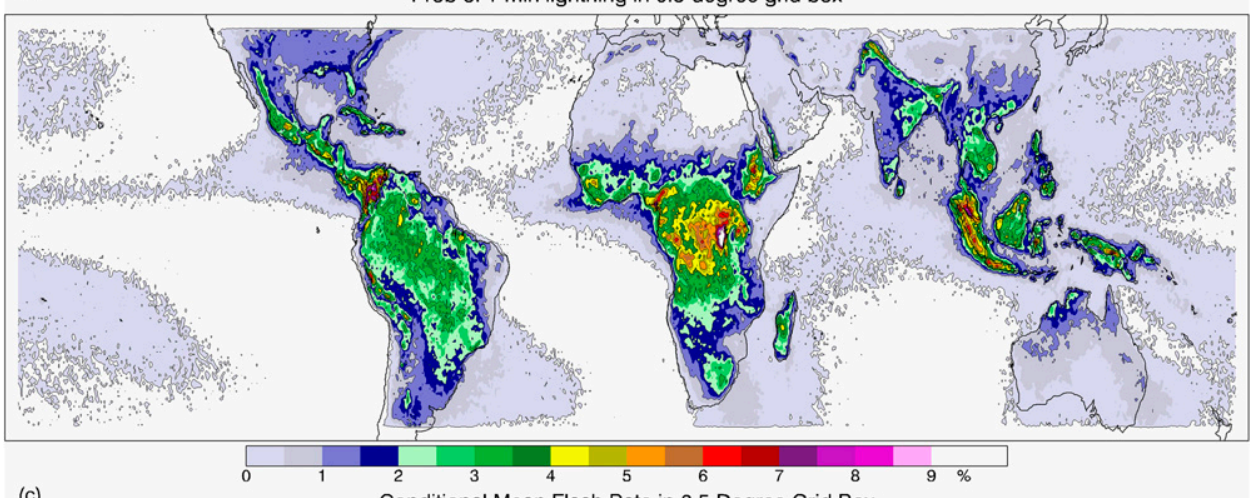

(c) Conditional Mean Flash Rate in 0.5-Degree Grid Box

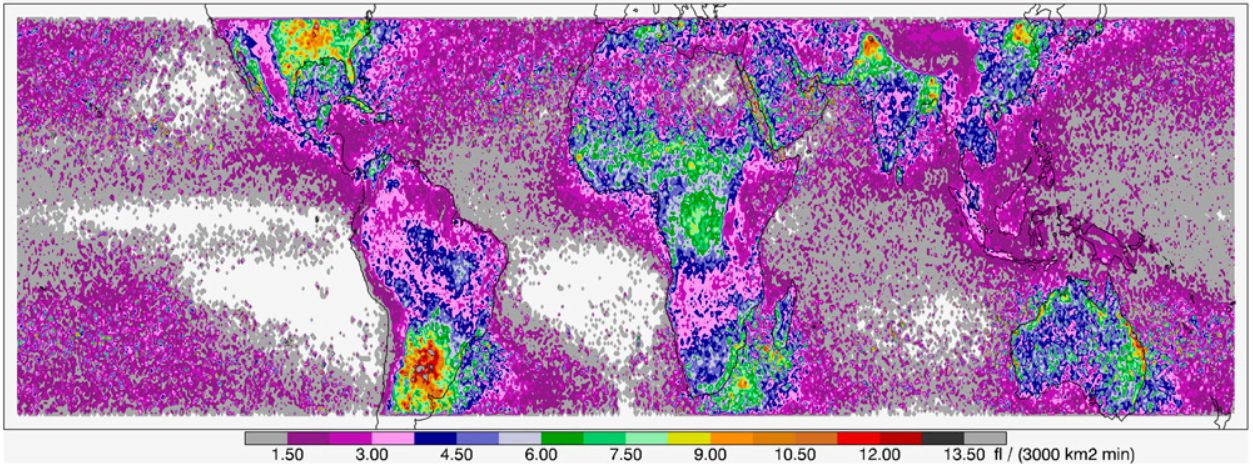

FIG. 2. (a) Mean annual flash rate observed by LIS on $0.5^{\circ} \times 0.5^{\circ}$ grid. (b) Fraction of observations with lightning in a $0.5^{\circ} \times 0.5^{\circ}$ grid box. (c) Conditional mean flash rate for $0.5^{\circ} \times 0.5^{\circ}$ grid boxes, taken as (a) divided by (b).

The rate is 7-10 flashes per minute for much of the southern United States but 2-5 flashes per minute for much of Brazil and around 3 flashes per minute for the Maritime Continent. Other locations with especially high conditional mean flash rates $(\sim 10$ flashes per minute) stretch along the southern flank of the Himalayas from Pakistan to eastern India, offshore southeast of South Africa, and along the coasts of Australia and eastern China.

The spatial patterns of conditional mean flash rate are consistent with the mean flashes per storm in Fig. 7 of
Boccippio et al. (2000). The Boccippio et al. (2000) study used only the first two years of LIS data, so that map appears much noisier than the ones presented here, but the general regions of high mean flash rates are similar. One key difference is that Boccippio et al. (2000) emphasized a result that per-storm flash rates differ (in a climatological average sense) by only about a factor of 2 between tropical land and tropical oceans. That may be true in Fig. 2c for the Amazon basin, the Maritime Continent, and eastern Africa in the deep tropics. But conditional mean flash rates for tropical central and 
(a)

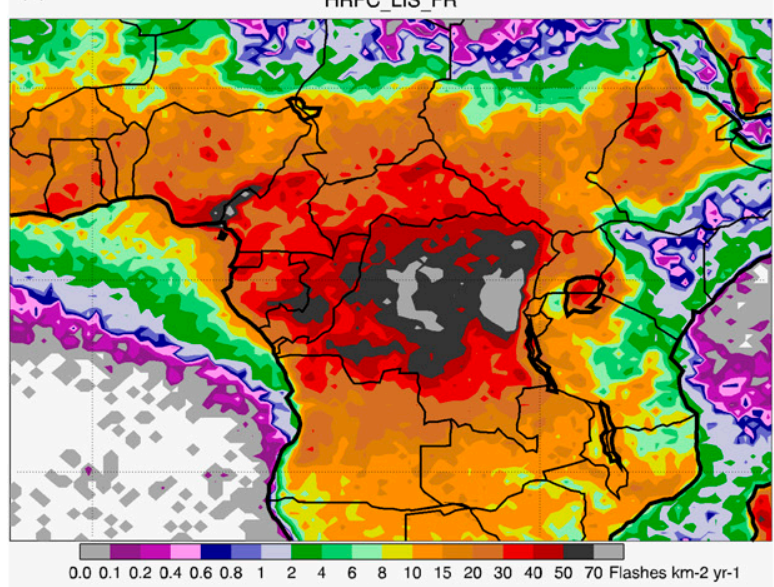

(b)

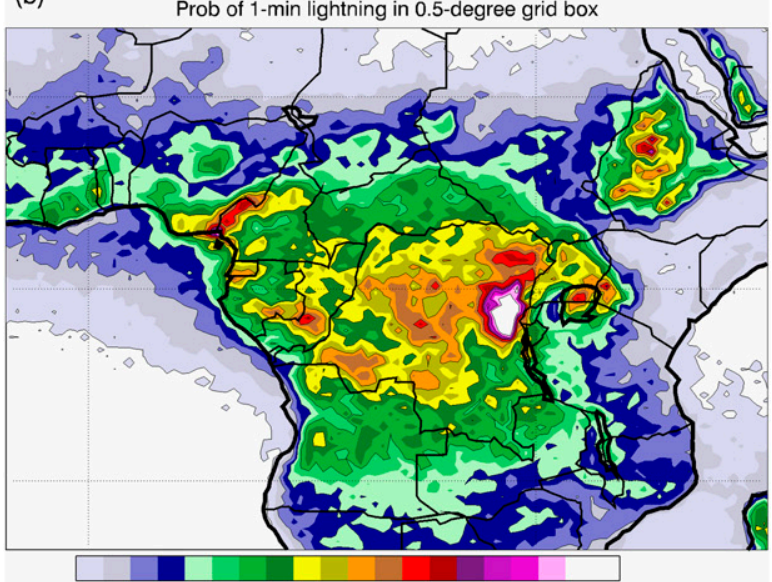

(c)

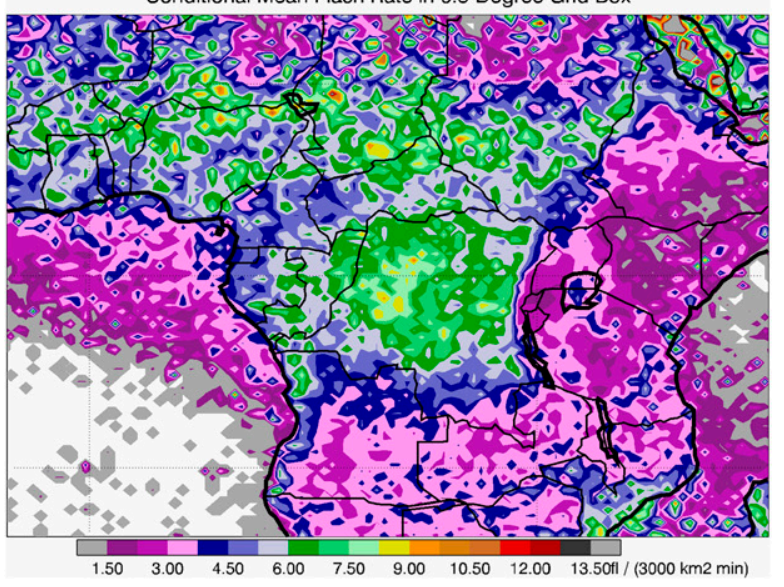

FIG. 3. As in Fig. 2, but zoomed in on Africa.

western Africa are about another factor of 2 higher. The rates in subtropical land regions are higher still.

An alternative computation of conditional mean flash rate can be made from the TRMM precipitation feature database described by Cecil et al. (2005) and Liu et al. (a)

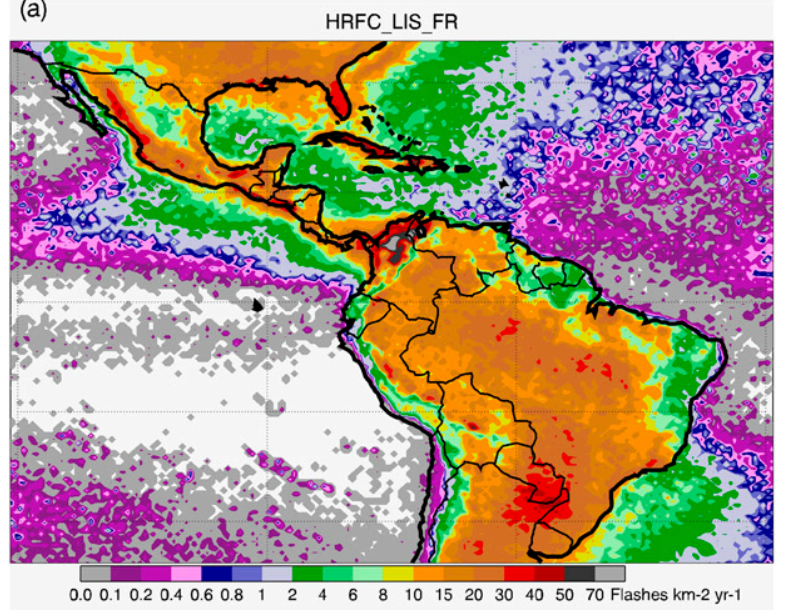

(b)

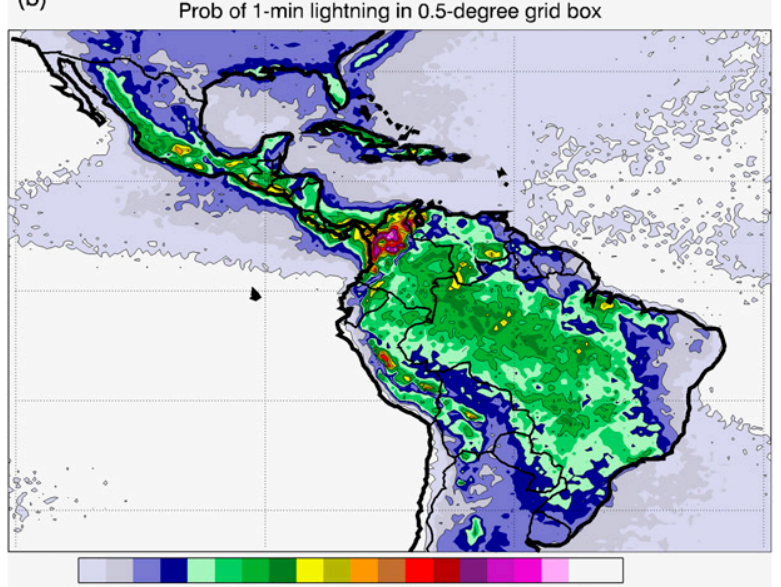

(c)

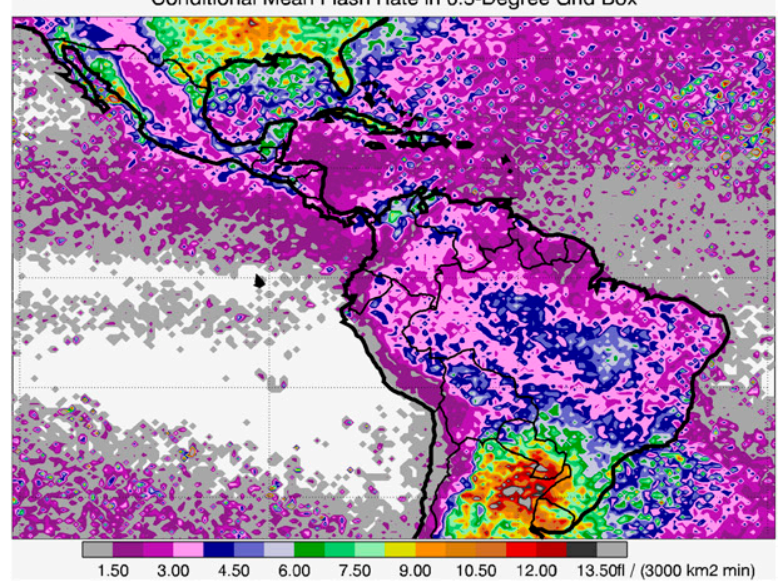

FIG. 4. As in Fig. 2, but zoomed in on the Americas.

(2008). All flashes across a mesoscale system are assigned to a single location for each precipitation feature in the Cecil et al. (2005) and Liu et al. (2008) database. Each precipitation feature has its own flash rate, which is the flash count divided by observation duration. Taking 
(a)

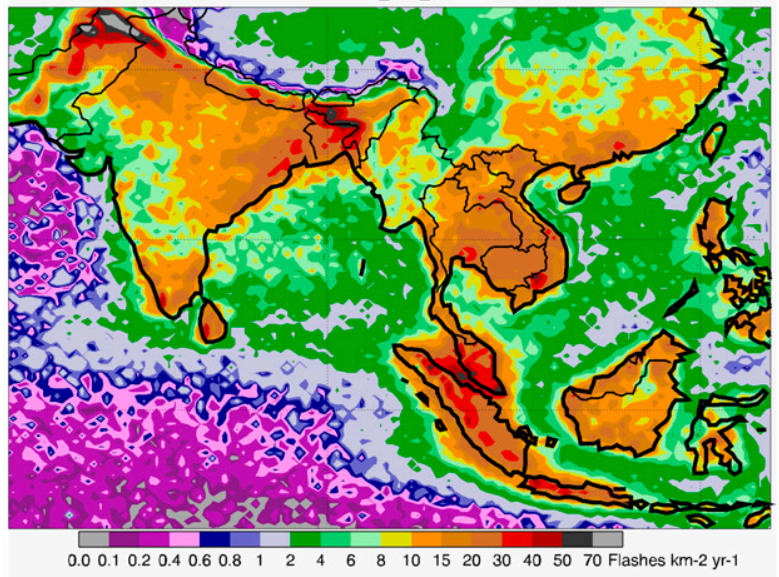

(b)

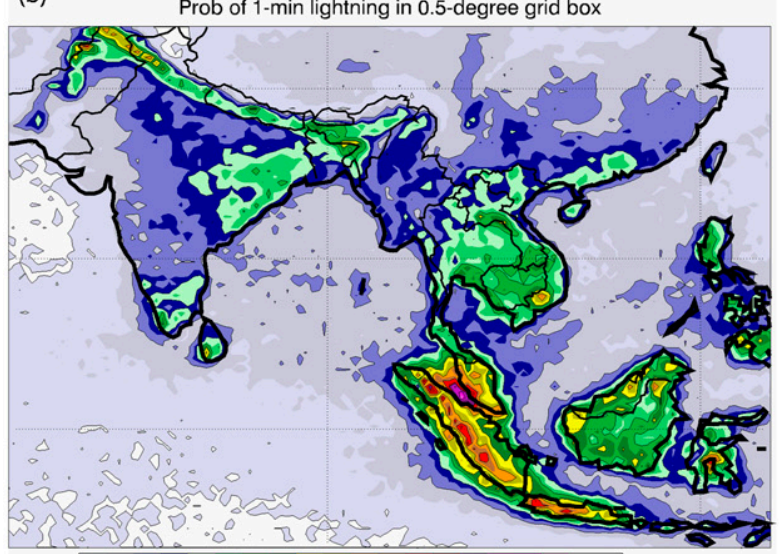

(c)

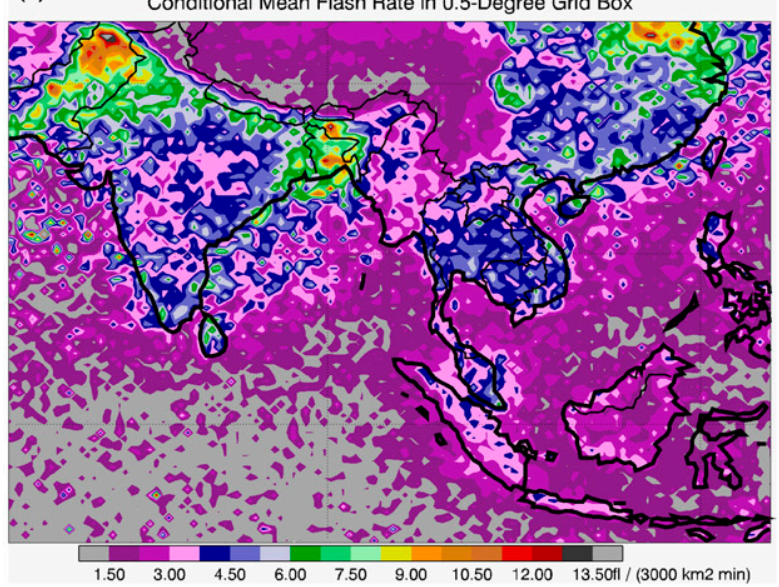

FIG. 5. As in Fig. 2, but zoomed in on South Asia. (a)
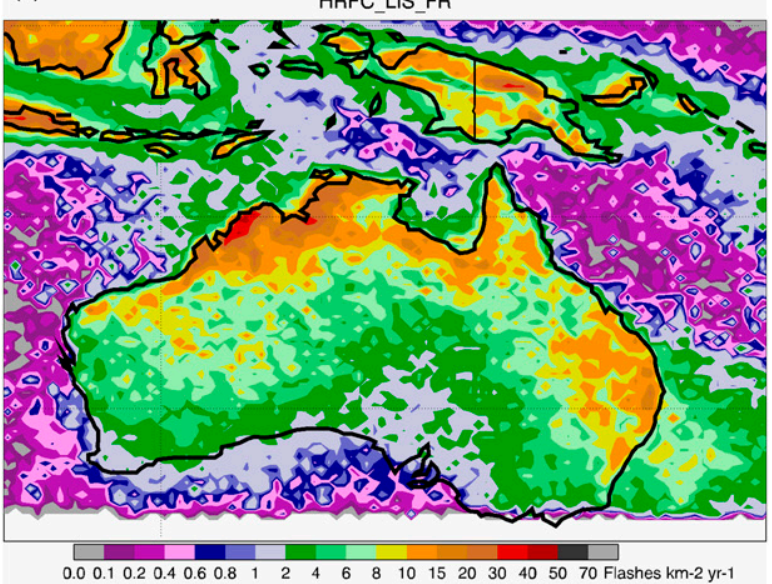

(b)

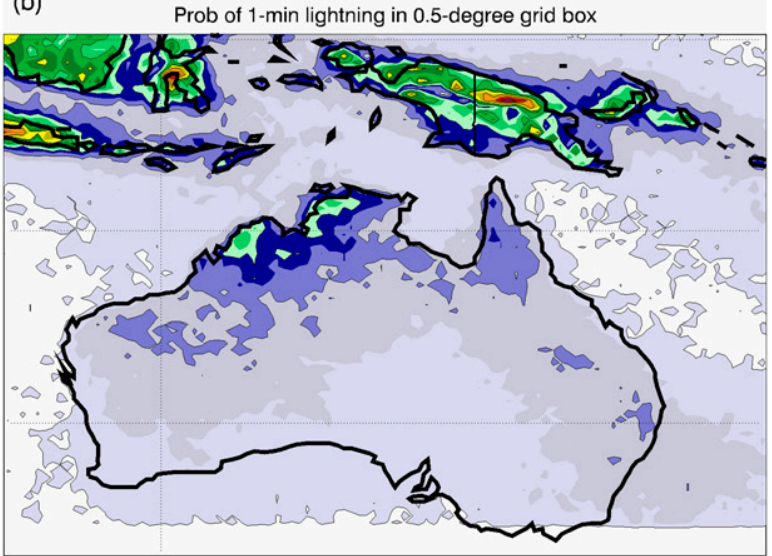

(c)

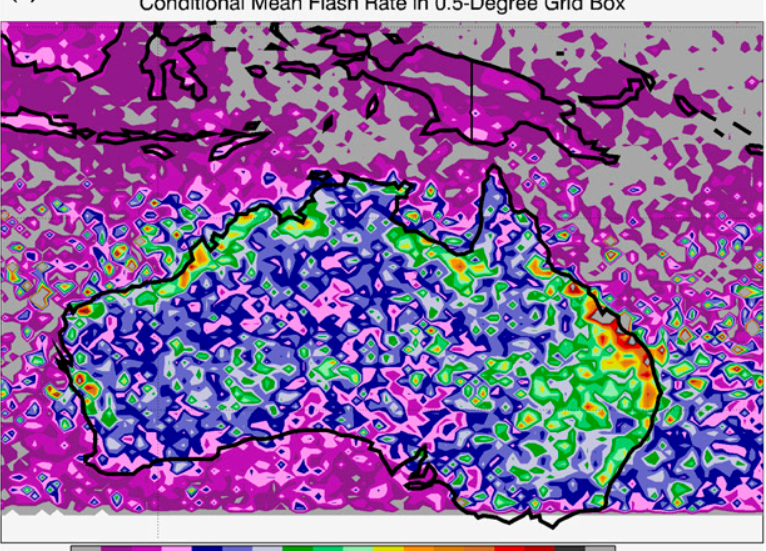

$\begin{array}{lllllllll}1.50 & 3.00 & 4.50 & 6.00 & 7.50 & 9.00 & 10.50 & 12.00 & 13.50 \mathrm{fll} /(3000 \mathrm{~km} 2 \mathrm{~min})\end{array}$

FIG. 6. As in Fig. 2, but zoomed in on Australia.

2013, the eight individual precipitation features having the highest flash rates (each in excess of 1000 flashes per minute, across large convective complexes) all occurred over subtropical South America or adjacent waters, where Fig. $2 \mathrm{c}$ shows the greatest conditional mean flash the mean flash rate from all the precipitation features with lightning in a grid box gives similar results as in Fig. 2c but with slightly higher values because the largest features actually exceed the size of the grid boxes studied here. With that database now updated through 
rates. In that same region, 17 of the 20 highest flash rate storms (with over 700 flashes per minute) and 34 of the 40 highest flash rates were found, with the remainder over the southern United States. Such rankings do not account for locations in the subtropics being sampled by more orbits than the deep tropics, but that is accounted for in Fig. 2 (and in subsequent figures).

Contrasts within central Africa (Fig. 3) are also noteworthy. There are separate maxima in mean annual flash rate in the central and eastern Congo (Fig. 3a), which were also observed by Bürgesser et al. (2013). The eastern maximum, bordered on the east by the Albertine Rift mountains, is associated with the highest probability of thunderstorm occurrence for individual observations, nearly $10 \%$. This maximum in probability of thunderstorm occurrence extends slightly farther east than the region of highest annual mean flash rates. This likely reflects a difference between more frequent thunderstorm initiation in the east and upscale growth as storms move westward. In the western maximum, $5 \%-6 \%$ of the observations have lightning in a $0.5^{\circ} \times$ $0.5^{\circ}$ grid box, and the conditional mean flash rate (around 8 flashes per minute) is slightly higher than farther east. All three of these fields have sharp gradients from the Congo eastward across Rwanda. The conditional mean flash rate there is only about 2 flashes per minute. The frequency of occurrence for thunderstorms in Rwanda is still relatively high compared to much of the rest of the world $(\sim 3 \%-4 \%$ of observations). These contrasts are also seen in Table 4 of Christian et al. (2003), with more than 200 thunder days per year for the stations in Rwanda and Uganda but slightly more than half that number farther west in the Congo. A local minimum with less than $2 \%$ of observations having lightning occurs in northwestern Tanzania, between Rwanda and Lake Victoria. There is a strong local maximum in thunderstorm occurrence over Lake Victoria itself ( $8 \%$ of observations), but with low conditional mean flash rates ( $\sim 4$ flashes per minute). Storms are very common over the northern part of the lake, but apparently not very strong.

\section{Time of day and time of year}

The deep convection that drives thunderstorms and lightning occurrence is often dependent on daytime heating and/or circulations that develop in response to differential heating. It can be more meaningful to look at the mean flash rate or the probability of thunderstorm occurrence as a function of time of day (and time of year, for most parts of the globe) than as a composite over all times and all seasons. This is treated in only a cursory manner in the present analysis. For simplicity in updating the LIS gridded climatology, the orbit counts as a function of time of day and day of year were stored on $2.5^{\circ} \times 2.5^{\circ}$ grids, as in the low-resolution diurnal climatology (LRDC), low-resolution annual climatology (LRAC), and low-resolution annual diurnal climatology (LRADC) flash rate products in Cecil et al. $(2014 a, b)$. These counts are for the number of orbits that fully sample (at least $80 \mathrm{~s}$ ) a $2.5^{\circ} \times 2.5^{\circ}$ grid box or that have lightning anywhere within the $2.5^{\circ} \times 2.5^{\circ}$ box. As a result, the orbit counts are lower and the fraction with flashes is higher than for the $0.5^{\circ} \times 0.5^{\circ}$ grid. The hotspots where lightning occurs in $8 \%-10 \%$ of observations on the $0.5^{\circ} \times 0.5^{\circ}$ grid in Fig. $2 \mathrm{~b}$ have values around $40 \%-50 \%$ on the $2.5^{\circ} \times 2.5^{\circ}$ grid. The values for the Amazon basin increase from $3 \%-4 \%$ probability of lightning anywhere in a $0.5^{\circ} \times 0.5^{\circ}$ grid box to around $30 \%$ probability anywhere in a $2.5^{\circ} \times 2.5^{\circ}$ grid box. Most of the southern United States increases from 1\%-2\% probability on the $0.5^{\circ} \times 0.5^{\circ}$ grid to about $10 \%$ probability on the $2.5^{\circ} \times 2.5^{\circ}$ grid.

An animation of the diurnal cycle of the probability of thunderstorm occurrence is shown in the online supplemental material. Considering late afternoon only, greater than $90 \%$ of the observations between 1600 and 1700 local solar time (LST; Fig. 7a) have lightning at the local maximum in east-central Africa. All across central Africa, tropical South America, the Maritime Continent, and Southeast Asia, at least $40 \%$ of observations during late afternoon have lightning within a $2.5^{\circ} \times 2.5^{\circ}$ grid box.

Lightning occurs least often in the morning hours, particularly the hours around and just after sunrise. Between 0800 and 0900 LST (Fig. 7b), most locations have lightning occurring in less than $5 \%$ of observations, and very few locations have lightning occurring more than $20 \%$ of the time. The local maxima where lightning does occur in more than $20 \%$ of the observations between 0800 and 0900 LST are almost all over water, near coasts (associated with land breezes) in otherwise high lightning environments. These especially occur where convergence is enhanced by curved or multiple coastlines, such as the coasts of Colombia and Panama, Lake Maracaibo nearby in South America (Bürgesser et al. 2012), Cameroon in west-central Africa, Lake Victoria in east-central Africa, and regions between islands and peninsulas of the Maritime Continent.

An animation of the annual variation of thunderstorm occurrence is shown in the supplemental material. It is most appropriate to consider both the diurnal and annual cycles, but the sampling gets small. Probabilities of lightning occurrence have been computed for bimonthly periods, with the diurnal cycle broken into 2-h intervals. This divides the few thousand orbits seen in Fig. 1b into 
(a)

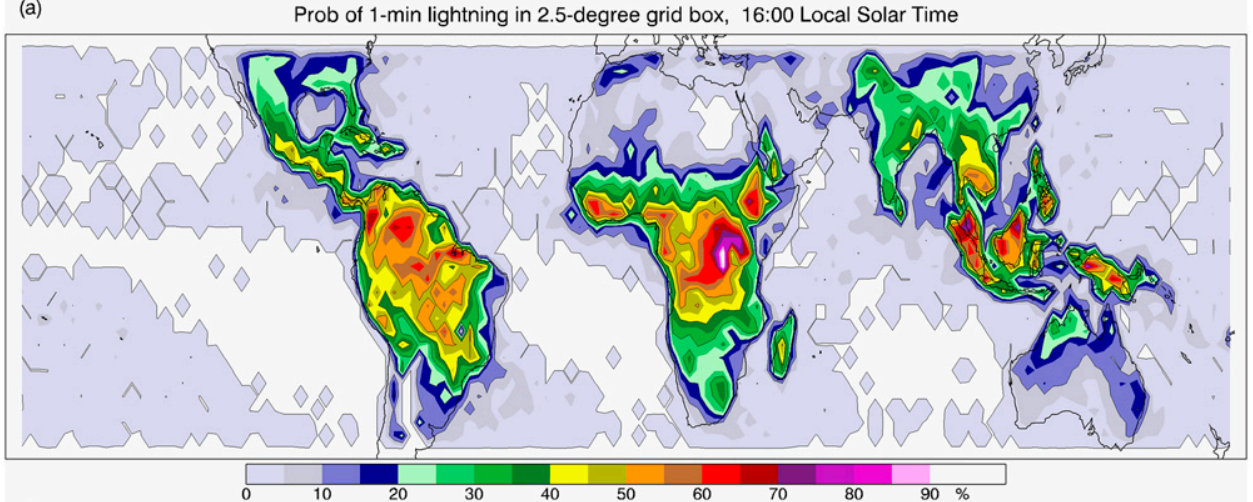

(b)

Prob of 1-min lightning in 2.5-degree grid box, 8:00 Local Solar Time

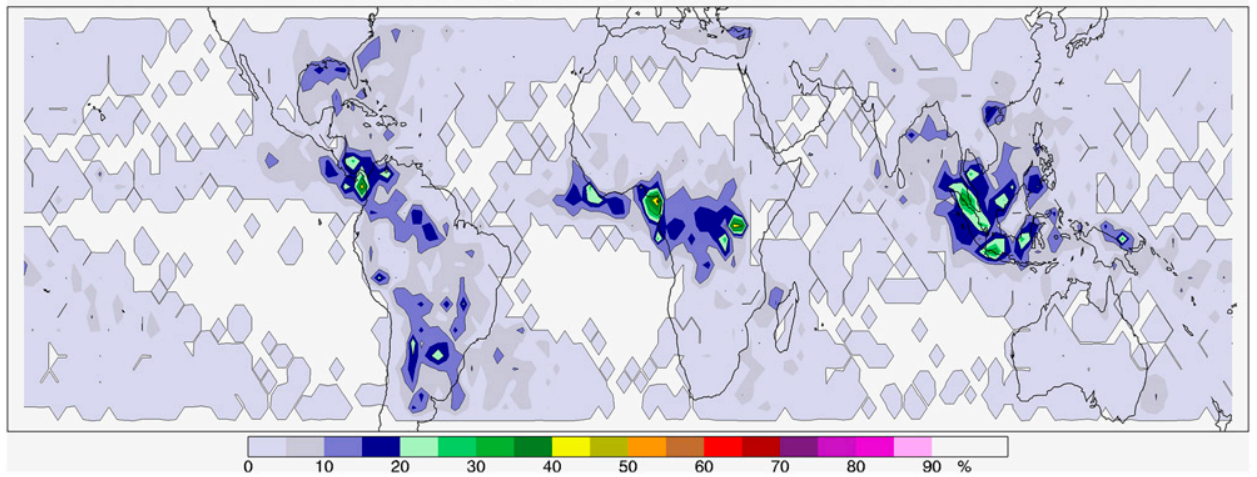

FIG. 7. (a) Fraction of observations with lightning in a $2.5^{\circ} \times 2.5^{\circ}$ grid box between 1600 and $1700 \mathrm{LST}$. (b) Fraction of observations with lightning in a $2.5^{\circ} \times 2.5^{\circ}$ grid box between 0800 and 0900 LST. (A loop of the diurnal cycle is available in the supplemental material.)

72 subsets, leaving tens of orbits to sample each grid box. Therefore, the maps look noisy, and precise details are not robust. Nevertheless, expected patterns can be seen in a general sense.

Figure 8 and the supplemental material map the fraction of observations having lightning for particular times of day and parts of the year. Figure 8a shows July and August (northern summer), between 2200 and 0000 UTC. Presenting this in terms of coordinated universal time (UTC) instead of local solar time (LST) is the result of using legacy processing routines to build the flash rate climatologies described by Cecil et al. (2014a). But that does give some sense of the diurnal cycle, with the time of day varying around the globe. Figure $8 \mathrm{a}$ is mid- to late afternoon across North America, and near sunrise for the Maritime Continent. In this example, LIS almost always sees lightning along the western mountains of Mexico on summer afternoons. More than half of the observations in southeastern United States during summer late afternoons have lightning within a $2.5^{\circ} \times 2.5^{\circ}$ grid box. Being winter in southern South America, the probabilities of lightning there are low (generally less than 10\%). During the late night in Africa, the winter portion of the continent is almost devoid of thunderstorms, but lightning occurs about $30 \%$ of the time for grid boxes farther north. A late night local maximum in Pakistan is a surprising feature of Fig. 8 and may be exaggerated by insufficient sampling. Farther east, much of the thunderstorm occurrence during these late night/early morning hours from India to Southeast Asia and the Maritime Continent is in the offshore regions.

Southern summer is similarly shown in Fig. $8 \mathrm{~b}$ for 1800-2000 UTC. Thunderstorm occurrence is concentrated in the Southern Hemisphere, in contrast to Fig. 8a. This is mid- to late afternoon across South America, and thunderstorms are common from the Andes to Bolivia and much of Brazil. This is evening in Africa, and parts of the region still have around 50\% probability of thunderstorms, but that is down from the afternoon peak.

\section{Discussion and conclusions}

Data from the LIS instrument on the TRMM satellite have been used to compute the frequency of occurrence of thunderstorms and the conditional mean lightning flash rate on a $0.5^{\circ} \times 0.5^{\circ}$ grid across the global tropics 
(a)

Prob of 1-min lightning in 2.5-degree grid box, JUL-AUG 23:00 UTC

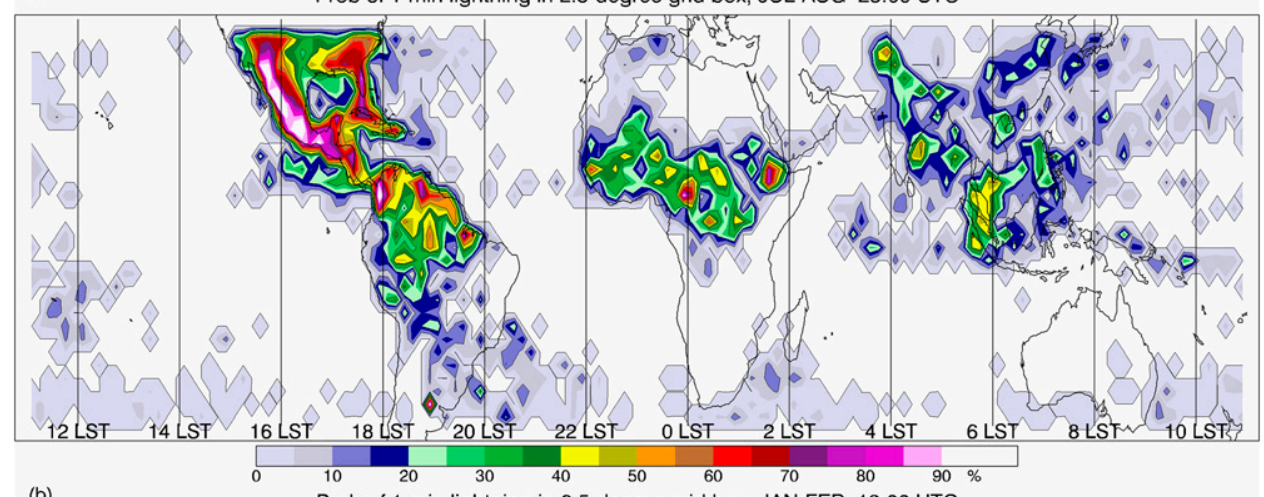

(b)

Prob of 1-min lightning in 2.5-degree grid box, JAN-FEB 19:00 UTC

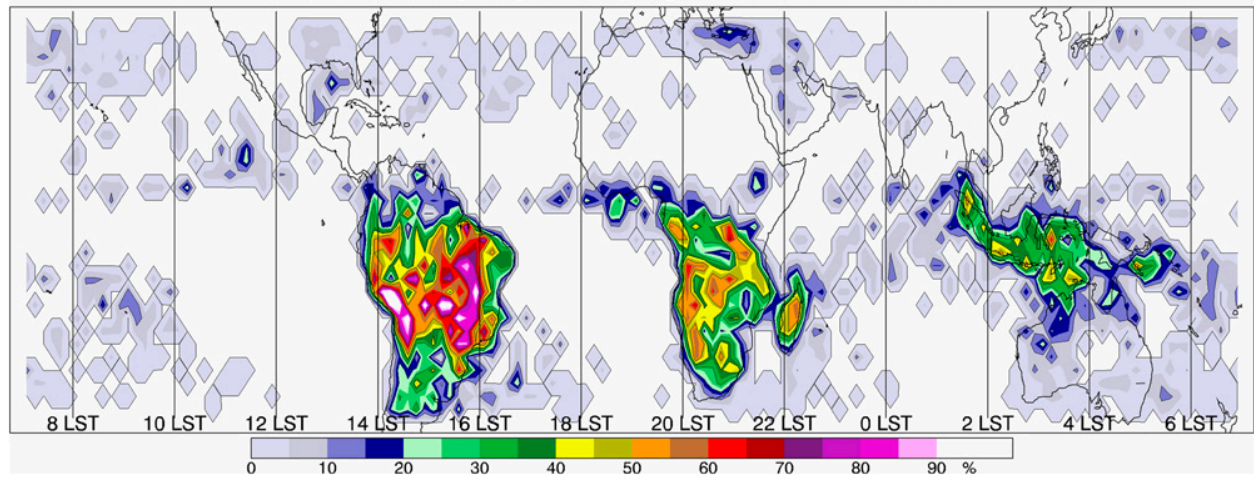

FIG. 8. Fraction of observations with lightning in a $2.5^{\circ} \times 2.5^{\circ}$ grid box between (a) 2200 and 0000 UTC during July and August. This is mid- to late afternoon for North America and near sunrise for East Asia and the Maritime Continent. (b) 1800-2000 UTC during January and February. This is mid- to late afternoon for South America, evening and early night for Africa, and late night for the Maritime Continent. (A loop of the annual diurnal cycle in 2-month, 2-h increments is available in the supplemental material.)

and subtropics. The diurnal cycle and annual cycle of thunderstorm occurrence has been computed on $2.5^{\circ} \times$ $2.5^{\circ}$ grids, with very basic examples shown here. In large part, the map of thunderstorm occurrence (Fig. 2b) has similarities to the map of annual mean flash rate (Fig. 2a), with exceptions in subtropical continental locations where the conditional mean flash rate is greatest.

The map of thunderstorm occurrence also has many general similarities to the map of annual thunderstorm days (Fig. 9a) compiled by WMO (1956), based on observers at surface meteorological stations reporting that thunder was heard. Since the "thunderstorm days" metric does not distinguish between days having many flashes and days having only a few, it is conceptually more similar to our fractional occurrence of thunderstorms than to annual mean flash rate or conditional mean flash rate. Both the thunderstorm day map from WMO (1956) and our fractional occurrence map in Fig. 9b (repeated from Fig. 2b, for easier comparison with thunderstorm days) have a more pronounced maximum in east-central Africa than does the map of annual mean flash rate (Fig. 2a). Both the thunderstorm days (Fig. 9a) and frequency of occurrence (Fig. 9b) have higher values in the Amazon basin of South America than in northern Argentina and Pakistan, where the annual mean flash rate (Fig. 2a) is higher.

Although our frequency of thunderstorm occurrence is not constructed to have the same meaning as a thunderstorm day-a location having multiple thunderstorms per day would have a high frequency of occurrence-some of the differences between Fig. 9a and Fig. 9b are most likely due to the measurement consistency from the satellite data and the inconsistency in scattered records from surface stations. For example, the thunderstorm day map in Fig. 9a shows several distinct maxima in Brazil, possibly due to differences in reporting characteristics at individual stations. The satellite data (Fig. 9b) show a more uniform distribution there. The thunderstorm day data in WMO (1956) lack any observations from Colombia or Venezuela in northwestern South America, where the satellite data show a very high frequency of thunderstorm occurrence 


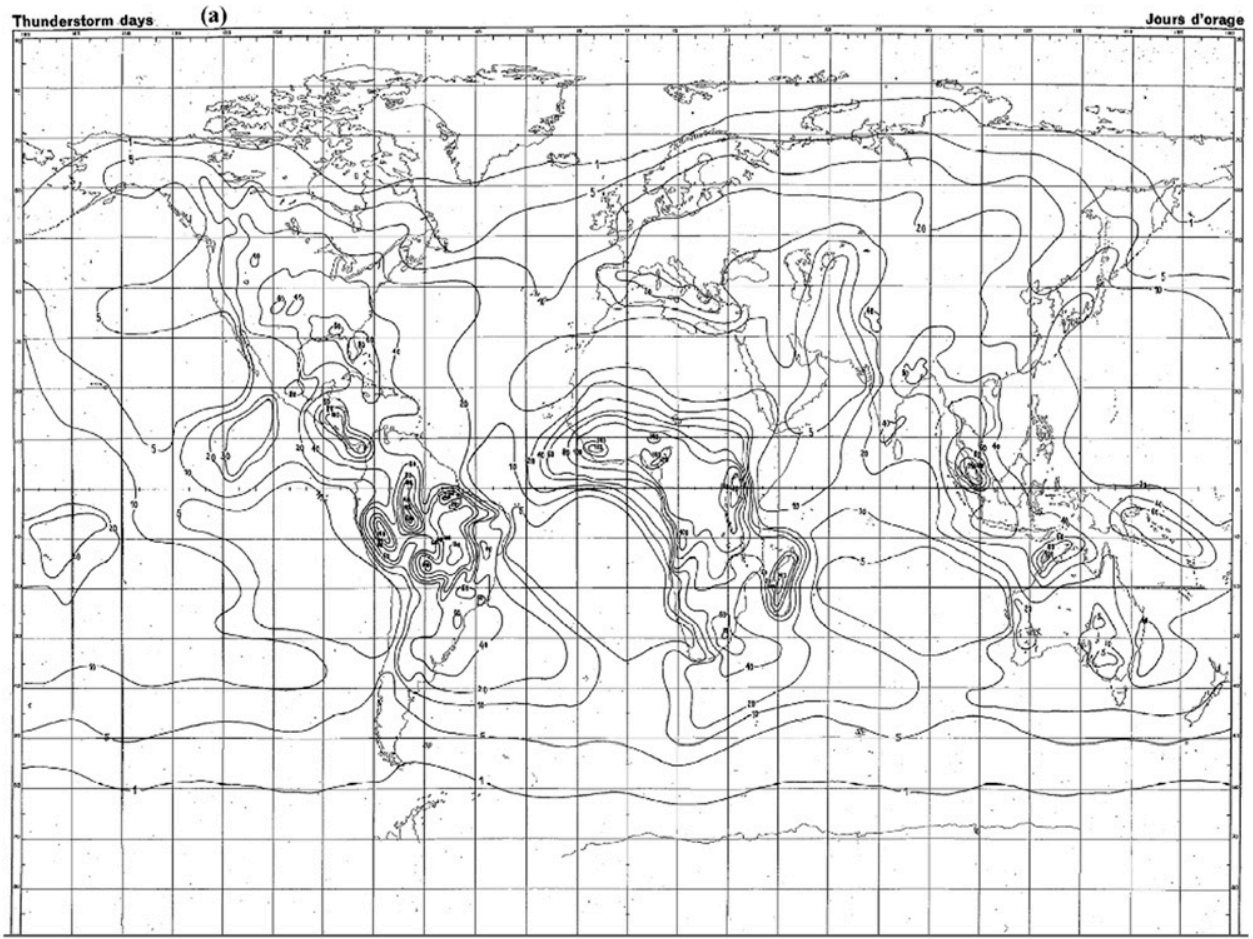

(b)

Prob of 1-min lightning in 0.5-degree grid box

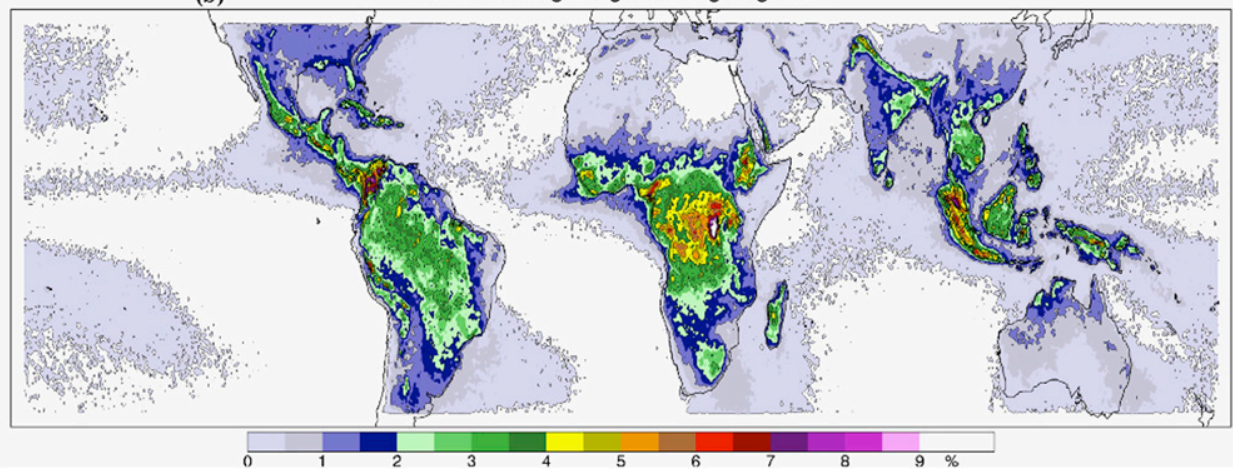

FIG. 9. (a) Mean annual thunderstorm days recorded by observers at surface meteorological stations. Reprinted from WMO (1956). (b) Fraction of observations with lightning, duplicated from Fig. 2b for comparison.

associated with the northern Andes and Lake Maracaibo. A thunderstorm day map for Venezuela from 1951 to 1971 (Diaz et al. 2009) includes values greater than 200 days per year along the Venezuela-Colombia border east of Lake Maracaibo. On the $0.5^{\circ} \times 0.5^{\circ}$ grid used here and at higher resolution used by Albrecht et al. (2011), TRMM LIS data show greater annual flash rates there than anywhere else on Earth.

Thunderstorms are observed most often over land in the deep tropics-particularly central Africa, the Maritime Continent, and northwestern South America (Fig. 2b). But the conditional mean lightning flash rates (Fig. 2c) are greater in certain subtropical continental locations, when storms do occur there. The greatest conditional mean flash rates are in northern Argentina and neighboring Paraguay, although storms occur there less often than farther north across Brazil. Conditional mean flash rates are also especially high in Pakistan, the south-central United States, eastern India and Bangladesh, eastern China, coastal Australia, and off the southeastern coast of Africa. Independent of lightning information, other satellite-based studies (Zipser et al. 2006; Cecil and Blankenship 2012) have also listed some of these locations as having the world's strongest storms, with northern Argentina and adjacent locations usually ranking first. 
Central Africa has both a high frequency of thunderstorm occurrence and a relatively high conditional mean flash rate-higher than the rest of the deep tropics. This combines to give central Africa the greatest annual mean lightning flash rate. There is a sharp gradient in conditional mean flash rate near the rift mountains of equatorial Africa. In the far eastern Democratic Republic of the Congo, there is the highest frequency of storm occurrence. Farther west, the frequency of occurrence decreases but the flash rate per occurrence increases.

Afternoon thunderstorms (Fig. 7a) drive the maximum described above in east-central Africa. More than $90 \%$ of the late-afternoon observations have lightning there. More generally across the deep tropics, close to half of the late-afternoon observations over land have lightning within almost any given $2.5^{\circ} \times 2.5^{\circ}$ grid box. The morning hours just after sunrise (Fig. 7b) generally have a minimum in thunderstorm occurrence over land. Prominent morning maxima are found in the deep tropics over water, but near curved coastlines, where convergent land-breeze circulations favor morning convection. These include the west coasts of Colombia and Cameroon, Lakes Maracaibo and Victoria, and regions between islands and peninsulas of the Maritime Continent. In the subtropics, thunderstorms become common on summer afternoons (Fig. 8), whereas their frequency of occurrence taken across the entire year (Figs. $7 \mathrm{a}$ and $2 \mathrm{~b}$ ) is much lower.

The raw data supporting these results are available from NASA's Global Hydrology Resource Center, with almost 100000 LIS science data files for individual TRMM orbits. Gridded climatologies of total mean flash rate [as in Fig. 2a; also for annual and diurnal cycles as described by Cecil et al. (2014a)] have been produced and distributed via GHRC. The new statistics presented here-the number of orbits sampling each grid box, the number of those observations with lightning, and the resulting computations of fractional thunderstorm occurrence and conditional mean flash rate-were generated for testing purposes during a recent update of the gridded flash rate climatology products. We anticipate including these for general distribution in the next release of the gridded climatology products, likely in midor late 2015. It remains to be determined whether these statistics will have the same smoothing applied as for analogous flash rate products described by Cecil et al. (2014a) or if the smoothing for those products will be changed in a future release.

Acknowledgments. This research benefits from over two decades of work by past and present members of the lightning team associated with NASA MSFC. In particular, the gridded climatologies were updated using source code originally developed by Dennis Boccippio. Sponsorship and support for the OTD and LIS data are from the NASA Earth Observing System and the Tropical Rainfall Measuring Mission. LIS and OTD data, including the gridded climatologies produced here, are distributed by the NASA EOSDIS Global Hydrology Resource Center DAAC, Huntsville, Alabama (http://lightning.nsstc.nasa.gov).

\section{REFERENCES}

Albrecht, R. I., S. J. Goodman, W. A. Petersen, D. E. Buechler, E. C. Bruning, R. J. Blakeslee, and H. J. Christian, 2011: The 13 years of TRMM Lightning Imaging Sensor: From individual flash characteristics to decadal tendencies. Proc. 14th Int. Conf. on Atmospheric Electricity, Rio de Janeiro, Brazil, International Commission of Atmospheric Electricity, M110203. [Available online at http://ntrs.nasa.gov/archive/nasa/ casi.ntrs.nasa.gov/20110015779.pdf.]

Boccippio, D. J., S. J. Goodman, and S. Heckman, 2000: Regional differences in tropical lightning distributions. J. Appl. Meteor., 39, 2231-2248, doi:10.1175/1520-0450(2001)040<2231: RDITLD>2.0.CO;2.

Bürgesser, R. E., M. G. Nicora, and E. E. Ávila, 2012: Characterization of the lightning activity of "Relámpago del Catatumbo." J. Atmos. Sol.-Terr. Phys., 77, 241-247, doi:10.1016/j.jastp.2012.01.013.

,-- , and -2013 : Spatial and time distribution of the flash rate over tropical Africa. J. Atmos. Sol.-Terr. Phys., 94, 41-48, doi:10.1016/j.jastp.2012.12.025.

Cecil, D. J., and C. B. Blankenship, 2012: Toward a global climatology of severe hailstorms as estimated by satellite passive microwave imagers. J. Climate, 25, 687-703, doi:10.1175/ JCLI-D-11-00130.1.

— S. J. Goodman, D. J. Boccippio, E. J. Zipser, and S. W. Nesbitt, 2005: Three years of TRMM precipitation features. Part I: Radar, radiometric, and lightning characteristics. Mon. Wea. Rev., 133, 543-566, doi:10.1175/MWR-2876.1.

- D. E. Buechler, and R. J. Blakeslee, 2014a: Gridded lightning climatology from TRMM-LIS and OTD: Dataset description. Atmos. Res., 135-136, 404-414, doi:10.1016/ j.atmosres.2012.06.028.

,$- \ldots$, and,$- 2014 \mathrm{~b}$ : LIS/OTD gridded lightning climatology data collection, version 2.3.2014. NASA EOSDIS Global Hydrology Resource Center Distributed Active Archive Center, accessed 30 June 2015, doi:10.5067/ LIS/LIS-OTD/DATA311.

Christian, H. J., and Coauthors, 2003: Global frequency and distribution of lightning as observed from space by the Optical Transient Detector. J. Geophys. Res., 108, 4005, doi:10.1029/ 2002JD002347.

Diaz, L., M. Martinez, J. Ramírez, and J. Rodriguez, 2009: Actualización de la actividad de rayos en Venezuela, empleando la información del proyecto satelital de la NASA. Congreso Venezolano de Redes y Energía Eléctrica, Porlamar, Venezuela, Comité Nacional Venezolano de CIGRÉ, B2-223.

Kuleshov, Y., G. De Hoedt, W. Wright, and A. Brewster, 2002: Thunderstorm distribution and frequency in Australia. Aust. Meteor. Mag., 51, 145-154. 
Liu, C., E. J. Zipser, D. J. Cecil, S. W. Nesbitt, and S. Sherwood, 2008: A cloud and precipitation feature database from nine years of TRMM observations. J. Appl. Meteor. Climatol., 47, 2712-2728, doi:10.1175/2008JAMC1890.1.

Negri, A. J., T. L. Bell, and L. Xu, 2002: Sampling of the diurnal cycle of precipitation using TRMM. J. Atmos. Oceanic Technol., 19, 1333-1344, doi:10.1175/1520-0426(2002)019<1333: SOTDCO $>2.0 . \mathrm{CO} ; 2$.

Williams, E., K. Rothkin, D. Stevenson, and D. Boccippio, 2000: Global lightning variations caused by changes in thunderstorm flash rate and by changes in the number of thunderstorms. J. Appl. Meteor., 39, 2223-2230, doi:10.1175/ 1520-0450(2001)040<2223:GLVCBC>2.0.CO;2.

WMO, 1956: World Distribution of Thunderstorm Days. Part 2: Tables of Marine Data and World Maps. WMO, $77 \mathrm{pp}$.

Zipser, E. J., C. Liu, D. J. Cecil, S. W. Nesbitt, and D. P. Yorty, 2006: Where are the most intense thunderstorms on Earth? Bull. Amer. Meteor. Soc., 87, 1057-1071, doi:10.1175/ BAMS-87-8-1057. 